\title{
An Integrated Approach to Prioritize Requirements using Fuzzy Decision Making
}

\author{
Vibha Gaur, Anuja Soni
}

\begin{abstract}
The success of a system depends upon how intensively it accomplishes its intended purpose by meeting all stakeholders' concerns pertaining to conflicting requirements such as cost, schedule, performance etc. Various stakeholders may have their individual and consolidated concerns over conflicting requirements. Individual concerns facilitate a stakeholder to obtain preference orderings of conflicting requirements and consolidated concerns assist developer to obtain consensual preference ordering that would satisfy all stakeholders. As the concerns over the conflicting requirements are vague, uncertain and subjective in nature, this paper employs Fuzzy Decision Making for modeling the vagueness, haziness and non-specificity associated with the requirements. Finally a case study using an agent oriented system is presented to illustrate the application of the methodology.
\end{abstract}

Index Terms - User Story Card (USC), Agent Card (AC), Agent oriented System (AOS), Goal_Points, Agent_Points.

\section{INTRODUCTION}

Requirements are prone to issues of disputes, collision of concerns, disparity and disagreement among the stakeholders $[1,2,3]$. Industrial organizations are constantly in search of new solutions and strategies for prioritizing the requirements which can accomplish the fuzzy and vague concerns of stakeholders concerning the conflicting requirements [4].

Requirements engineering provides the appropriate mechanism for resolving ambiguities, vagueness and fuzziness subject to the conflicting concerns of stakeholders $[5,6]$. Various requirements negotiation and prioritization techniques have been reported in literature $[1,7,8,9,10]$ that help the developers to obtain consensus among stakeholders. A prioritization method using relationship matrix contemplates multiple perspectives of stakeholders that utilizes the concept of correlation to compute weighted priorities of requirements [1]. Simulation method prioritizes the requirements of mixed strategies using agile and plan based approach [7]. Prioritization using Cost and benefit method establishes the importance of cost and benefit pertaining to every requirement [8]. Analytical Hierarchy Process (AHP) is a multiple-criteria decision-making technique that uses a pair wise comparison matrix to compute the relative value of requirements with respect to one another [9].Cluster based automated method expresses various concerns of stakeholders to multiple categories of requirements such as feature based, non functional and other cluster requirements [10]. However, these techniques of prioritization don't consider the uncertainty and fuzziness

Department of Computer Science, University of Delhi, Delhi, India (e-mail: 3.vibha@gmail.com,30.anuja@gmail.com). associated with the requirements. Secondly, these methods don't take into account the goals and constraints associated with the conflicting requirements that may lead to stakeholders' dissatisfaction.

This paper employs individual fuzzy decision making to capture the subjectivity encapsulated in individual concerns of stakeholders with respect to goals and constraints of conflicting requirements and hence facilitates them to obtain preference orderings of conflicting requirements that reflects their individual concerns. Secondly this paper utilizes multi-person decision making to resolve diverse concerns of various stakeholders. These integrated set of requirements would satisfy all stakeholders and also assist the developer to ascertain the essential requirements of stakeholders within limited resources.

The application of the methodology is illustrated using Agent oriented Paradigm (AOP) that is a recent way of representing the requirements of a system in terms of agents. An Agent-oriented System (AoS) typically involves a large number of agents playing different roles, interacting with each other to achieve individual and common goals [11]. Software agents are computer programs that act autonomously on behalf of their users across open and distributed environments to solve growing number of complex problems. In an agent-oriented system, various stakeholders may differ over the implementation issues of agents. In addition, they may have their own individual and consolidated concerns associated with goals and constraints associated with conflicting requirements e.g. cost of accomplishing a system may be a conflicting requirement for various stakeholders. They may have their own priorities over cost in terms of goals and constraints associated with it. Goal associated with the cost may be to enhance the return of an organization but not at the stake of quality of service. This paper takes into account goals and constraints associated with the conflicting requirements and obtain an integrated set of requirements using Fuzzy Decision-Making that would satisfy all the stakeholders.

The organization of the paper is as follows: Section II introduces Fuzzy Decision-Making. Section III utilizes Fuzzy Decision-Making to deal with individual and consolidated concerns of stakeholders to prioritize requirements. Section IV illustrates the proposed methodology using an agent oriented system.

\section{BRIEF INTRODUCTION TO FUZZY DECISION-MAKING}

Fuzzy decision making attempts to deal with the vagueness and uncertainty inherent in human formulation of preferences, constraints and goals that is accomplished by fuzzy set theory [12]. Fuzzy Set Theory generalizes ordinary or classical sets 
in an attempt to model and simulate human thought and linguistic reasoning in a domain characterized by incomplete, imprecise, uncertain and vague data $[13,14,15]$.In a fuzzy system, the variables are regarded as linguistic variables to enable computation with words. A fuzzy number [16] is characterized by a fuzzy interval of real numbers, each with a grade of membership between 0 and 1 . Generally In applications it is often convenient to work with triangular fuzzy numbers because of their computational simplicity [17].

Triangular fuzzy numbers are expressed as $(1, \mathrm{~m}, \mathrm{u})$ and the parameters $1, \mathrm{~m}$, and $\mathrm{u}$ respectively indicate the smallest value, the most promising value and the largest possible value that describe a fuzzy event $[13,17]$. The membership function of a triangular fuzzy number is defined as:

$$
\mathrm{f}(\mathrm{w})=\left\{\begin{array}{cc}
0 & \mathrm{x}<\mathbb{1} \\
\frac{\mathrm{x}-\mathbb{1}}{\mathrm{m}-\mathbb{d}} & \mathbb{1} \leq \mathrm{x} \leq \mathrm{m} \\
\frac{\mathrm{w}-\mathrm{w}}{\mathrm{w}} & \mathrm{m} \leq \mathrm{x} \leq \mathrm{u} \\
\mathrm{m} & \mathrm{x} \geq \mathrm{w}
\end{array}\right\}
$$

As fuzzy numbers are difficult to deal with, a most promising crisp value may facilitate to reach at some substantial concluding results. An $\alpha$-cut is viewed as a bridge between fuzzy sets and crisp sets. In literature, $\alpha$-cut of a fuzzy set A is defined as the crisp set that contains all the elements whose membership grades in A are greater than or equal to the specified value of $\alpha$ [12]. Thus higher value of $\alpha$ indicates higher confidence in that parameter and implies that stakeholders are more confident about the persistence of most promising crisp value of a fuzzy number in a smaller range of crisp interval owing to higher value of $\alpha$. Value of $\alpha=0.5$ shows the moderate level of confidence in most promising crisp value. The crisp interval ${ }^{\alpha} \mathrm{A}$ by $\alpha$-cut operation against fuzzy number $(1, \mathrm{~m}, \mathrm{u})$ can be obtained as $[13,16]$ :

$$
a_{A}=\left[1^{\alpha}, u^{\alpha}\right]=\left[(m-1) \alpha+\mathbb{1}_{x}-(u-m) \alpha+u\right]
$$

Crisp values against the crisp intervals representing the degree of optimism for decision makers, can be computed as $[13,30]$ :

$$
\mathrm{C}_{\text {ai }}^{\mu}=\mu I_{\text {au }}+(1-\mu) I_{\text {ail }} \text { where } \mu \in[0,1]
$$

Where $I_{\alpha l}=$ lower bound of crisp interval, $I_{\alpha u}=$ upper bound of crisp interval, $\mu$ is called as the index of optimism representing optimistic level of decision maker as optimistic, moderate or pessimistic. Higher value of $\mu$ represents the higher degree of optimism.

Applications of fuzzy decision-making have been employed in various problems such as voting paradoxes [18], recruitment systems [19], obtaining consensus [20] and facility location selection [21], Mass Customization Markets [22] etc.

A decision situation reflecting the individual concerns can be characterized by the following components:

- A set of possible actions/alternatives

- A set of goals each of which is expressed in terms of a fuzzy set.
- A set of constraints where each constraint is expressed by a fuzzy set.

Fuzzy Decision-Making involving several decision makers facilitates to obtain a group choice consisting of certain level of agreement, namely $\alpha$ where the ordering is complete [12]. The $\alpha$-cuts divide the total scale [0,1] into a number of levels $\alpha$ and assists to obtain best precedence ordering subjected to a compatible total ordering for a specific $\alpha$.

\section{AN INTEGRATED APPROACH TO REQUIREMENTS PRIORITIZATION}

Projects fail to set right expectations and address conflicting requirements of stakeholders [23]. A holistic approach is required to deal with individual and consolidated concerns of stakeholders so that the system developed on these integrated concerns may satisfy all stakeholders' requirements. This paper employs Fuzzy Decision-Making to deal with the vagueness and uncertainty associated with individual and consolidated concerns of stakeholders in an AOS.

In the previous work [24, 28], the requirements of users were recorded in a set of user story cards (USCs) developed jointly by customer representatives and the development team. USCs were mapped to Agent Cards (ACs) to define characteristics of an agent in terms of goals and tasks. The same framework is considered for this work also. Various stakeholders may have conflicting requirements over the implementation of agents in an AoP.

This section describes an integrated approach to deal with individual and consolidated concerns of the stakeholders so that the system developed on these concerns may obtain the prioritized list of requirements that may satisfy all the stakeholders. The integrated approach is explained in following sub-sections.

\section{A. Dealing with individual concerns}

Several classes of decision making problems are recognized by many researchers $[12,26]$. Decision problem involving a single decision maker is referred to as individual decision making. Many algorithms including AHP and B-Tree are available in literature to obtain the preference order of the requirements. But many of these lack analysis of requirements in terms of associated goals and constraints so as to reach to an optimal decision. Also, these do not address fuzzy concerns of stakeholders. This paper intends to capture the subjectivity in the stakeholders' concerns using fuzzy decision making and applies individual decision-making to resolve individual concerns of stakeholders pertaining to goals and constraints of conflicting requirements. The algorithm presented below assists stakeholders in analyzing their conflicting requirements in terms of goals and constraints to reach to a crisp optimal decision value against which an appropriate priority can be assigned to the conflicting requirement. In this approach a decision is determined by an appropriate intersection of fuzzy goals and constraints.

Various parameter and variables involved in the analysis are described below: 
$\mathrm{k}=(1 \ldots \mathrm{m})$, where $\mathrm{m}$ : number of conflicting requirements $\mathrm{s}=(1 \ldots \mathrm{n})$, where $\mathrm{n}$ : number of stakeholders

$\mathrm{i}=(1 \ldots \mathrm{g})$, where $\mathrm{g}$ : number of goals w.r.t. $\mathrm{k}^{\text {th }}$ conflicting requirement

$\mathrm{j}=(1 \ldots \mathrm{c})$, where $\mathrm{c}$ : number of constraints w.r.t. $\mathrm{k}^{\text {th }}$ conflicting requirement

$\mathrm{X}_{\mathrm{sk}}$ : weight/priority assigned to $\mathrm{k}^{\text {th }}$ conflicting requirement w.r.t. $\mathrm{s}^{\text {th }}$ stakeholder.

$\mu_{\text {Gki }}$ : membership function defined on $i^{\text {th }}$ goal $G_{k i}$ w.r.t. $k_{\text {th }}$ conflicting requirement specified

$\mu_{\mathrm{Ckj}}$ : membership function defined on $\mathrm{j}^{\text {th }}$ constraint $\mathrm{C}_{\mathrm{kj}}$ w.r.t. $\mathrm{k}_{\mathrm{th}}$ conflicting requirement.

$\mu_{\mathrm{Dk}}$ : final optimal decision w.r.t. weight of $\mathrm{k}^{\text {th }}$ conflicting requirement in the form of a fuzzy set.

$D_{k}$ : final optimal decision in the form of a crisp value

$\mathrm{v}_{\mathrm{ki}}$ : Weights assigned to set of goals $\mathrm{G}_{\mathrm{ki}}(\mathrm{k}=1 . . \mathrm{m}, \mathrm{i}=1,2 \ldots \mathrm{g})$

$\mathrm{w}_{\mathrm{kj}}$ :Weights assigned to set of constraints $\mathrm{C}_{\mathrm{kj}}$ $(\mathrm{k}=1 . . \mathrm{m}, \mathrm{j}=1,2 \ldots \mathrm{c})$

$\mu_{\text {Gki }}^{\text {vki }}$ Weight factor w.r.t. $\mathrm{G}_{\mathrm{ki}}$.

$\mu^{\text {wkj }}$ : Weight factor w.r.t. $C_{k j}$.

Several suggestions have been made to decision-making issue in literature [12, 29]. One of the method introduced by Yager has become very popular that introduces weight factors as power indices and uses a conjunctive operator [26, 31]. Optimal decision fuzzy set $\mu^{\mathrm{w}}{ }_{\mathrm{Dk}}$ using minimum operator is obtained as:

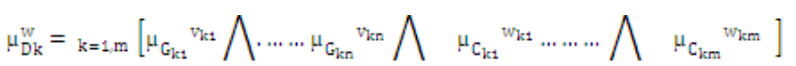

Crisp decision point $\mathrm{D}_{\mathrm{k}}$ can be derived by the formula:

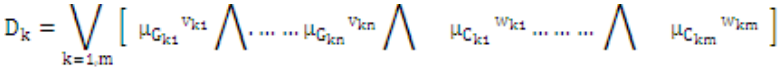

$$
\begin{aligned}
& \text { Where } \bigvee=\max \cdot \Lambda=\min
\end{aligned}
$$

The equations (4) and (5) are used to obtain optimal goal associated with a given constraint. More is the importance given to a goal, more will be the influence on the aggregated result. And less is the importance given to a constraint, the more will be the influence on a goal and thus reducing the aggregated result.

The algorithm to deal with individual concerns involves the following steps:

1) Identify a common scale for the weight/priority of all conflicting requirements $R_{1}, R_{2} \ldots \ldots R_{n}$.

Scales of weights in linguistic terms are shown in TABLE I.

2) Identify goals $G_{k i}$ and constraints $C_{k j}$ associated with every conflicting requirement $k$. Where $i=1 \ldots g, j=1 \ldots c$

3) Obtain membership functions for both the fuzzy sets $G_{k i}$ and $\mathrm{C}_{\mathrm{kj}}$ w.r.t. $\mathrm{k}_{\mathrm{th}}$ conflicting requirement. Membership function w.r.t. goal $\mathrm{G}_{\mathrm{ki}}$, directly proportional to the weight/priority $\mathrm{X}_{\mathrm{sk}}$ of a conflicting requirement $\mathrm{k}$ is defined as:

$$
\mu_{\mathrm{G}_{\mathrm{kif}}}=\left\{\begin{array}{cl}
0 & \mathrm{X}_{\mathrm{sk}} \leq \mathrm{a} \\
1+\frac{\mathrm{X}_{\mathrm{gk}}-\mathrm{b}}{\mathrm{b}-\mathrm{a}} & \mathrm{a}<\mathrm{X}_{\mathrm{gk}} \leq \mathrm{b} \\
1 & \mathrm{X}_{\mathrm{sk}}>\mathrm{b}
\end{array}\right.
$$

Where $\mathrm{s}=1 \ldots \mathrm{n}, \mathrm{k}=1 \ldots \mathrm{m}, \mathrm{i}=1 \ldots \mathrm{g}$

For the values of $X_{\text {sk }}$ between $a$ and $b$, the value of membership function increases as $\mathrm{X}_{\mathrm{sk}}$ increases, keeping the value in between $[0,1]$. After a threshold value $b$, value of membership function becomes stagnant.

Membership function showing the inversely proportional nature of constraint $\mathrm{C}_{\mathrm{kj}}$, w.r.t. $\mathrm{X}_{\mathrm{sk}}$ is framed as.

$\mu_{\mathrm{c}_{\mathrm{ki}}}=\left\{\begin{array}{cr}1 & 0 \leq \mathrm{N}_{\mathrm{sk}} \leq \mathrm{a} \\ \frac{\mathrm{b}-\mathrm{a}}{\mathrm{a} \mathrm{N}_{\mathrm{sk}}} & \mathrm{a}<\mathrm{X}_{\mathrm{sk}} \leq b \\ 0 & \mathrm{~N}_{\mathrm{sk}}>b\end{array}\right.$

Where $\mathrm{k}=1 \ldots \mathrm{m}, \mathrm{j}=1 \ldots \mathrm{c}$

The value of $\mathrm{a}$ and $\mathrm{b}$ are set as a threshold limit and may be decided as per the nature/functionality of a goal and a constraint.

TABLE I SCALES W.R.T. WEIGHTS/PRIORITIES IN LINGUISTIC TERMS

\begin{tabular}{|c|c|}
\hline Weights/priority in linguistic terms & Scales \\
\hline Very less important (VLS) & $0-3$ \\
\hline Less important (LS) & $1-5$ \\
\hline Important (I) & $3-7$ \\
\hline Highly important (HI) & $5-9$ \\
\hline Very highly important (VHI) & $7-11$ \\
\hline
\end{tabular}

4) Obtain the values of weights $v_{k i}$ and $w_{k j}$ respectively for $\mathrm{G}_{\mathrm{ki}}$ and $\mathrm{C}_{\mathrm{kj}}$ (where $\mathrm{k}=1 . . \mathrm{m}, \mathrm{i}=1 . . \mathrm{g}, \mathrm{j}=1 . . \mathrm{c}$ ) from various stakeholders using linguistic terms.

5) Compute crisp values against these obtained fuzzy weights. Following sequence of steps assist developers to reach to the crisp values associated with fuzzy weights:

5.1) Place these fuzzy linguistic terms on a scale of triangular fuzzy numbers.

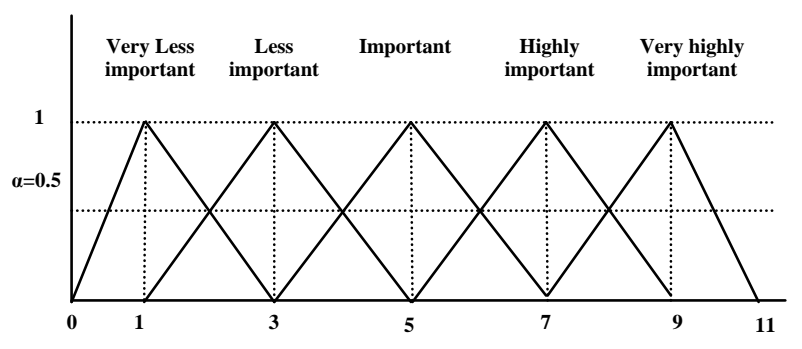

Figure 1. A scale of degree of weights in triangular fuzzy numbers

5.2) Crisp intervals at a given level of confidence coefficient $\alpha$ given are obtained by the equation (2). A crisp interval $\left[1 \alpha, u_{\alpha}\right]$ called as interval of confidence corresponding to a fuzzy number $(1, \mathrm{~m}, \mathrm{n})$ facilitates a developer to confine to that interval for which membership value goes up a certain limit $\alpha$.

5.3) Obtain crisp values against the crisp intervals obtained in the previous step as given by the equation (3). This crisp value represents degree of optimism and facilitates a stakeholder to switch from 
the crisp interval to a single most promising value. Assuming the same level of optimism for all stakeholders, the value of index of optimism $\mu$ is kept fixed for all stakeholders. The value of weight thus obtained is divided by summation of all obtained weights to keep the value in $[0,1]$.

6) Plot the weight factors $\mu_{\text {Gki }}^{\text {vki }}$ and $\mu^{\text {wkj }}$ Ckj against priority/weight $\mathrm{X}_{\mathrm{sk}}$ assigned to conflicting requirements on the scale specified in Fig.1 and obtain their intersection using equation (4).

7) Obtain a crisp decision value using equation (5).

8) Repeat the process for all conflicting requirements.

9) Arrange the obtained crisp decision values in decreasing order of values of weights/priorities to obtain preference ordering of conflicting requirements $R_{1}, R_{2} \ldots R_{n}$.

This ordered list of conflicting requirements ultimately reflects individual concerns of stakeholders. The above algorithm deals with fuzziness and vagueness inherent in the minds of stakeholders and assists them to obtain preference ordering of conflicting requirements such as $\mathrm{P}_{1}=\left\langle\mathrm{R}_{1}, \mathrm{R}_{3}, \mathrm{R}_{4} \ldots\right\rangle$. The preference orderings of various stakeholders are used by a developer to obtain integrated set of requirements that may reflect their consolidated concerns.

\section{B. Dealing with consolidated concerns}

Requirement Negotiation is concerned with resolving the conflicting requirements of various stakeholders to reach to an optimum set of requirements on which all stakeholders would agree $[1,2,3]$. This paper utilizes simple and easy to implement method [12] to negotiate conflicting requirements that results in an integrated set of requirements reflecting consolidated concerns of all stakeholders.

The negotiation algorithm to deal with consolidated concerns of all stakeholders is described as follows:

1) Identify conflicting requirements say $R=R_{1}, R_{2} \ldots R_{m}$. Let $P_{i}$ be the precedence ordering of $n$ stakeholders over $\mathrm{m}$ conflicting requirements given as,

$\mathrm{P}_{1}=\left\langle\mathrm{R}_{3}, \mathrm{R}_{1}, \mathrm{R}_{5} \ldots \ldots \ldots \mathrm{R}_{\mathrm{m}}\right\rangle$

$\mathrm{P}_{2}=\mathrm{P}_{5}=\left\langle\mathrm{R}_{4}, \mathrm{R}_{1}, \mathrm{R}_{3} \ldots \ldots . ., \mathrm{R}_{\mathrm{m}-1}\right\rangle$

$\mathrm{P}_{\mathrm{n}}=\left\langle\mathrm{R}_{2}, \mathrm{R}_{5}, \mathrm{R}_{1} \ldots \ldots ., \mathrm{R}_{\mathrm{m}}\right\rangle$ etc.

Membership function for every $R_{i}$ over $R_{j}$ is computed by by dividing the number of stakeholders preferring $\mathrm{R}_{\mathrm{i}}$ to $R_{j}$, by total number of stakeholders $n$.

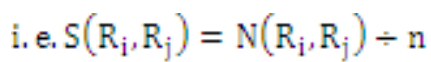

2) Obtain Social relation $S: R \times R \rightarrow[0,1]$ consisting of values of membership function for every pair $\left(R_{i}, R_{j}\right)$

3) Obtain $\alpha$-cuts. All values in $S$ are treated as the various levels of $\alpha$; $\alpha$-cuts denoted by ${ }^{\alpha} S$ are those set of ordered pairs $\left(R_{i}, R_{j}\right)$ for which value of membership function is greater than or equal to $\alpha$.

4) Determine the compatible total ordering for a specific $\alpha$.

The above algorithm attempts to find a value of $\alpha$ against which a compatible total ordering could be achieved that ensures the final settlement of conflicting requirements on which all stakeholders would agree. Process of finding $\alpha$-cuts is continued till total ordering is achieved which ultimately is treated as the final consensus on conflicting requirements and represents the consolidated concerns of all stakeholders.

The ordering thus obtained above assists the developers to obtain prioritized list of requirements.

\section{Prioritizing the Requirements}

With high customer expectations, tight schedules, and limited resources, prioritization is used to deliver the most essential functionality as early as possible [27, 12]. An integrated set of requirements achieved through best precedence ordering assists the developers to prioritize requirements of agents using goal_points and agent_points [28]. Goal_points is defined as a feasibility measure for achieving the goal of an agent within assigned estimates. Higher value of a goal_point signifies that goal is more viable to achieve.

Suppose in an AOS,

$\mathrm{m}$ : number of conflicting requirements

$r$ : number of agents

$\mathrm{t}:$ number of goals of an agent

Computation of agent_points of an agent that finally leads to prioritization of agents, involves mainly the following steps:

1) Refine the weights obtained in previous sub section $X_{1}$, $\mathrm{X}_{2} \ldots \mathrm{X}_{\mathrm{m}}$ against optimum ordering by calculating variance of these weights and average of all weights.

2) Compute the goal_points $G_{P i j}(i=1,2 \ldots r ; j=1,2 \ldots t)$ for all the agents over the conflicting requirements as:

$$
\mathrm{GP}_{\mathrm{ij}}=\sum_{\mathrm{k}=1}^{\mathrm{m}} \mathrm{Y}_{\mathrm{k}} * \mathrm{X}_{\mathrm{k}}
$$

$y_{k}$ for a particular goal is defined as the relative value of a conflicting requirement and is computed as the ratio of minimum of all the values of a conflicting requirement to the actual value of that requirement for a particular goal.

3) Compute the agent points $\left(\mathrm{AP}_{\mathrm{i}}\right)$ for Agents by summing all $\mathrm{GP}_{\mathrm{ij}}$ of associated $\mathrm{G}_{\mathrm{j}}$, where $\mathrm{i}=1,2 \ldots \mathrm{r}$, $\mathrm{j}=1,2 \ldots \mathrm{t}$

$$
A P_{i}=\sum_{j=1}^{t} G P_{i j}
$$

4) Arrange ACs in descending order of APs to obtain order of implementation of various agents in decreasing order of consensus.

It has been seen that the goal_points computed using equation (9) have value between $(0,1)$. Low value of goal_points signifies a complex requirement with lower probability of achieving a goal. Agent_points of an agent is computed from summation of its associated goal_points that supports the developer in prioritizing the agents in an AOS.

\section{CASE Study}

To illustrate the proposed methodology, a case study of Material Management Agent Oriented System was performed $[24,28]$. The aim of the study is to prioritize the 
requirements that are represented using Agent cards (ACs). In the process of prioritization, various stakeholders may have their own concerns and priorities for the precedence ordering of the conflicting requirements such as cost (C), schedule $(\mathrm{SH})$, functionality $(\mathrm{F})$, performance $(\mathrm{P})$ and risk (R). These individual and consolidated concerns need to be resolved to satisfy all stakeholders in a system. Weights/priorities assigned to these conflicting requirements w.r.t. number of stakeholders $(s=1 \ldots n)$ are represented as $\mathrm{X}_{\mathrm{s} 1}, \mathrm{X}_{\mathrm{s} 2}, \mathrm{X}_{\mathrm{s} 3}, \mathrm{X}_{\mathrm{s} 4}, \mathrm{X}_{\mathrm{s} 5}$ respectively. Individual concern obtains the preference ordering of $\mathrm{C}, \mathrm{SH}, \mathrm{P}, \mathrm{F}, \mathrm{R}$ for each stakeholder and consolidated concern assists to obtain the optimal preference ordering from individual preference orderings.

\section{Dealing with individual concerns}

Seven stakeholders were selected for the study. Every stakeholder was asked to obtain preference ordering of conflicting requirements $\mathrm{R}_{1}: \mathrm{C}, \mathrm{R}_{2}: \mathrm{SH}, \mathrm{R}_{3}: \mathrm{F}, \mathrm{R}_{4}: \mathrm{P}, \mathrm{R}_{5}$ : R. Indentified goals $(\mathrm{G})$ and constraints $(\mathrm{C})$ associated with these conflicting requirements are listed below in Table II :

TABLE II IDENTIFIED GOALS AND CONSTRAINTS W.R.T. CONFLICTING REQUIREMENTS

\begin{tabular}{|c|l|l|}
\hline $\begin{array}{l}\text { Priority of } \\
\text { conflicting } \\
\text { requirements }\end{array}$ & Goals(G) & Constraints(C) \\
\hline Cost & $\begin{array}{l}\text { Enhance net } \\
\text { profit of an } \\
\text { organization }\end{array}$ & High performance is desirable \\
\hline Schedule & $\begin{array}{l}\text { Availability of } \\
\text { system on time }\end{array}$ & $\begin{array}{l}\text { To develop the system with } \\
\text { desired performance/functionality } \\
\text { within assigned budget. }\end{array}$ \\
\hline Functionality & $\begin{array}{l}\text { To obtain } \\
\text { system as per } \\
\text { customers' } \\
\text { requirements }\end{array}$ & $\begin{array}{l}\text { To develop the system in assigned } \\
\text { budget and schedule }\end{array}$ \\
\hline Performance & $\begin{array}{l}\text { Obtain } \\
\text { customers' } \\
\text { satisfaction }\end{array}$ & $\begin{array}{l}\text { To develop the system in assigned } \\
\text { budget and schedule }\end{array}$ \\
\hline $\begin{array}{l}\text { Ro deal with } \\
\text { failures of } \\
\text { project }\end{array}$ & $\begin{array}{l}\text { To develop the system as per } \\
\text { desired performance and within } \\
\text { assigned budget and schedule }\end{array}$ \\
\hline
\end{tabular}

The goal of each stakeholder is to obtain the optimal decision value of goal and constraint w.r.t. every conflicting requirement. These optimal decision values facilitate a stakeholder to obtain values of weights/priorities of conflicting requirements so as to reach to their preference orderings.

For this case study 15 experts were consulted to settle on the values of $a=3, b=7$ for the membership function of goals and $a=3, b=10$ for the membership function of constraints respectively.

Stakeholder $S_{I}$ 's decision making regarding the priorities/weights of conflicting requirements such as cost, schedule, functionality, performance and risk: $\mathrm{S}_{1}$.

$\mathrm{X}_{11}$ : Weight/priority assigned to cost w.r.t. stakeholder

Weight/priority $\mathrm{X}_{11}$ w.r.t. cost is to be decided in such a manner against which an optimum balance of profit (goal) and quality (constraint) can be maintained. Profit of industry is directly proportional to priority assigned to cost. Less or very less importance/priority given to cost would always lead to less profit and more importance/concentration assigned to cost definitely would lead to higher profit.

Profit would lie between $[0,1]$. Initially industry does not give priority to cost, so the profit remains nil. But after certain duration of time, industry becomes more money oriented and gives priority to cost as well to earn profit. After a threshold limit of 7 i.e. against priority of cost falling amongst "I","HI" and "VHI", profit irrespective of priority given to cost becomes stagnant and resumes the value 1 .

Assuming values of a as 3 and threshold limit $b$ as 7 the membership function (6) for profit w.r.t. weight/priority of $\operatorname{cost}(\mathrm{C})$ can be re-written as:

$$
\mu_{\text {Profit }_{11}}=\left\{\begin{array}{cr}
0 & X_{11} \leq 3 \\
1+\frac{\mathrm{X}_{11}-7}{4} & 3<\mathrm{X}_{11} \leq 7 \\
1 & \mathrm{X}_{11}>7
\end{array}\right.
$$

Optimal level of weight/priority corresponding to cost can be derived as the intersection of the quality of requirements and profit of industry. Quality of requirements is inversely proportional to the weight of cost. So as LI or VLI is assigned to the cost, quality incorporated remains at higher level as less concern for cost may result in improved quality. As industry becomes more money oriented, pays more heed to cost and less to the quality, would result in degradation of quality of service.

Substituting $a=3$ and $b=10$ in equation (7), membership function for quality (constraint) can be rewritten as:

$$
\mu_{\text {Quality11 }}=\left\{\begin{array}{cc}
1 & 0 \leq \mathrm{X}_{11} \leq 3 \\
\frac{7}{3 \mathrm{X}_{11}} & 3<\mathrm{X}_{11}<10 \\
0 & \mathrm{X}_{11}>10
\end{array}\right.
$$

TABLE III WEIGHTS IN LINGUISTIC TERMS ASSIGNED TO GOALS/CONSTRAINTS IN RESPECT OF COST BY STAKEHOLDER $S_{1}$

\begin{tabular}{|c|c|c|c|}
\hline Stakeholder & $\begin{array}{c}\text { goals and } \\
\text { constraints }\end{array}$ & $\begin{array}{c}\text { Weights assigned in } \\
\text { fuzzy terms }\end{array}$ & $\begin{array}{c}\text { Range } \\
\text { representing } \\
\text { the weights }\end{array}$ \\
\hline \multirow{2}{*}{$\mathbf{S}_{1}$} & Profit & Between "I", "HI" & $(6,7,8)$ \\
\cline { 2 - 4 } & Quality & Between "I", "HI" & $(6,7,8)$ \\
\hline
\end{tabular}

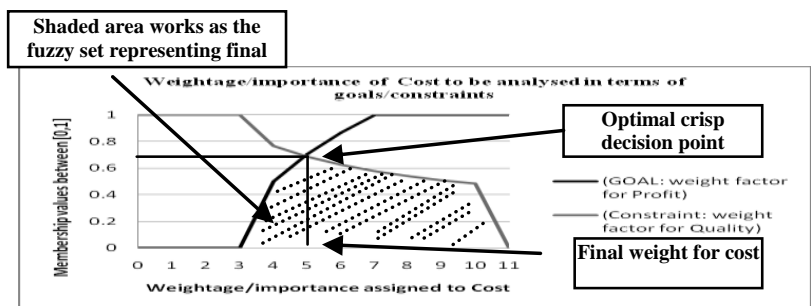

Figure 2. Optimal priority of cost against intersection of weight factors pertaining to profit and quality

Various stakeholders express their concern for various goals and constraints in linguistic terms pertaining to various conflicting requirements. E.g. Stakeholder $S_{1}$ observing quality somewhere between "Important" and "Highly important" assigns the triangular fuzzy number $(6,7,8)$ to it and due to being equally concerned for the profit of industry, keeps the profit among somewhere "Important" and "Highly 
important" category, therefore assigns the triangular fuzzy number $(6,7,8)$ to it as shown in TABLE III.

From the fuzzy weights obtained by stakeholders as taken in TABLE III nothing concrete can be interpreted, as overlapping of the membership functions allows a weight to belong to more than one set at the same time. These need to be converted to some crisp values.

Crisp intervals against these fuzzy numbers are obtained below from equation (2), where value of $\alpha$ is assumed to be fixed and taken as 0.5 that represents the moderate confidence level of stakeholders:

$\mathrm{v}_{1}:(6,8,9)=[(3-2) *(0.5)+2,-(4-3)(0.5)+4]=[2.5,3.5]$

$\mathrm{w}_{1}:(6,7,8)=[6.5,7.5]$

Crisp values against crisp intervals are obtained below from equation (3), where value of $\mu$ is assumed to be fixed and taken as 0.5 representing the moderate optimistic level:

For crisp value of $\mathrm{v}_{1}=(6,7,8)=7$

Crisp value of $\mathrm{w}_{1}=(6,7,8)=7$

Scaling these weights in $[0,1]$ :

Value of $v_{1}$ in $[0,1]=v_{3} /\left(w_{3}+v_{3}\right)=7 /(7+7)=0.5$

Value of $\mathrm{w}_{1}$ in $[0,1]=\mathrm{w}_{3} /\left(\mathrm{w}_{3}+\mathrm{v}_{3}\right)=7 /(7+7)=0.5$

TABLE IV YAGER'S METHOD TO OBTAIN WEIGHT/PRIORITY OF COST W.R.T. GOAL/CONSTRAINT BY STAKEHOLDER $\mathrm{S}_{1}$

\begin{tabular}{|c|c|c|c|c|c|}
\hline $\begin{array}{c}\text { Weights/ } \\
\text { priorities } \\
\text { w.r.t. cost: } \\
\left(\mathrm{A}_{\mathrm{s} 1}\right) \\
(\mathrm{s}=1)\end{array}$ & $\begin{array}{l}\text { Profi } \\
\text { t: } \\
\left(\mu_{G_{11}}\right)\end{array}$ & $\begin{array}{l}\text { Weight } \\
\text { factor } \\
\text { for } \\
\text { profit: } \\
\left(\|_{G_{11}}{ }^{w_{11}}\right)\end{array}$ & $\begin{array}{l}\text { Quality: } \\
\left(\mu_{C_{11}}\right)\end{array}$ & $\begin{array}{c}\text { Weight } \\
\text { factor for } \\
\text { quality: } \\
\left(\|_{\mathrm{C}_{11}} \mathbb{1}_{11}\right)\end{array}$ & $\begin{array}{c}\text { Intersecti } \\
\text { on(min) } \\
\text { of weight } \\
\text { factor for } \\
\text { profit and } \\
\text { quality }\end{array}$ \\
\hline & & \multicolumn{4}{|c|}{ Optimal points of decision (max value) } \\
\hline 0 & 0 & & $T$ & 1 & 0 \\
\hline 1 & 0 & & 1 & 1 & 0 \\
\hline 2 & 0 & 0 & 1 & 1 & 0 \\
\hline 3 & 0 & 0 & 1 & & 0 \\
\hline 4 & 0.25 & 0.5 & 0.5833 & 0.763763 & 0.5 \\
\hline 5 & 0.5 & 0.70711 & 0.4667 & 0.68313 & 0.68313 \\
\hline 6 & 0.75 & 0.86603 & 0.3889 & 0.62361 & 0.62361 \\
\hline 7 & 1 & 1 & 0.3333 & 0.57735 & 0.57735 \\
\hline 8 & 1 & 1 & 0.2917 & 0.540062 & 0.540062 \\
\hline 9 & 1 & 1 & 0.2593 & 0.509175 & 0.509175 \\
\hline 10 & 1 & 1 & 0.2333 & 0.483046 & 0.483046 \\
\hline 11 & 0 & 0 & 1 & 1 & 0 \\
\hline
\end{tabular}

In TABLE IV maximum value of intersection of weight factor for profit and quality $=0.68313$ and against this value, weight/priority of cost on $\mathrm{x}$-axis falls as 5 . Hence value of optimal level of weight/priority assigned to cost is 5 against which an optimum balance of profit and quality can be maintained.

Similarly for next conflicting requirement schedule (SH), following membership function for goal (availability of system) and constraint (performance of system), can be obtained as:

$\mu_{\text {Axsilability21 }}=\left\{\begin{array}{c}0 \\ 1+\frac{\mathrm{X}_{12}-7}{4}\end{array}\right.$

$$
\begin{aligned}
\mathrm{X}_{12} & \leq 3 \\
3<\mathrm{X}_{12} & \leq 7 \\
\mathrm{X}_{12} & \geq 7
\end{aligned}
$$

So far as importance/priority given to schedule is less or very less i.e. $\mathrm{X}_{12} \leq 3, \mathrm{~s} / \mathrm{w}$ product cannot be made timely at all. As importance/priority given to schedule increases till the limit of 7 , tendency for the product to be developed timely also increases. And after more importance/priority is given to schedule i.e. $X \geq 7$, timely availability reaches to its maximum limit 1 and after this limit even if more weight/priority is assigned to schedule by putting more efforts, availability of $\mathrm{s} / \mathrm{w}$ product remains stagnant at its higher limit.

$\mu_{\text {Performance }_{21}}=\left\{\begin{array}{c}1 \\ \frac{7}{3 \mathrm{X}_{12}} \\ 0\end{array}\right.$

$$
\begin{aligned}
0 & \leq \mathrm{X}_{12} \leq 3 \\
3<\mathrm{X}_{12} & \leq 10 \\
\mathrm{X}_{12} & >0
\end{aligned}
$$

If less priority or very less priority is given to $\mathrm{SH}$, then more efforts can be put in to obtain higher quality. And similarly as and when more priority is given to schedule then the quality will be effected.

This case study addresses on one goal and one constraint and the same process can be extended to more goals and constraints as well.

Fuzzy weight from stakeholder $\mathrm{S}_{1}$ w.r.t. goals and constraints of schedule are obtained from TABLE V. Crisp weights against fuzzy weights in TABLE $\mathrm{V}$, obtained as:

$$
\begin{aligned}
& \mathrm{v}_{2}=(8,10,11)=[(10-8) *(0.5)+8,-(11-10)(0.5)+11]=[9,10.5]= \\
& =(0.5) *(10.5)+(1-0.5) *(9)=9.75 \\
& \mathrm{w}_{2}=(6,7,8)=7
\end{aligned}
$$

TABLE V WEIGHTS IN LINGUISTIC TERMS ASSIGNED TO GOALS/CONSTRAINTS IN RESPECT OF SHEDULE

\begin{tabular}{|c|c|c|c|}
\hline Stakeholder & $\begin{array}{c}\text { goals and } \\
\text { constraints }\end{array}$ & $\begin{array}{c}\text { Weights assigned } \\
\text { in fuzzy terms }\end{array}$ & $\begin{array}{c}\text { Range } \\
\text { representing } \\
\text { the weights }\end{array}$ \\
\hline \multirow{2}{*}{$\mathrm{S}_{\mathbf{1}}$} & Availabilty & $\begin{array}{c}\text { Between "HI" and } \\
\text { "VHI" }\end{array}$ & $(8,10,11)$ \\
\cline { 2 - 4 } & Performance & Between "I", "HI" & $(6,7,8)$ \\
\hline
\end{tabular}

Converting these weights in $[0,1]$ :

Value of $\mathrm{v}_{2}$ in $[0,1]=\mathrm{v}_{1} /\left(\mathrm{w}_{1}+\mathrm{v}_{1}\right)=9.75 /(9.75+7)=0.58209$

Value of $\mathrm{w}_{2}$ in $[0,1]=\mathrm{w}_{1} /\left(\mathrm{w}_{1}+\mathrm{v}_{1}\right)=(7 /(7+9.75))=0.41791$

If more accuracy needs to be required then using equations (13) and (14) membership values can be calculated against continuous values i.e. fractional values as well such as $0.1,0.2 \ldots 1,1.1 \ldots 1.9,2,2.1 \ldots 3,3.1 \ldots .3 .9,4 \ldots .5,5.1,5.2 \ldots .$. and so on. In the above graph, intersection of weight factor for timely availability and performance comes out between 5 and 6 therefore against intersection point 5.5 on $\mathrm{x}$-axis may be chosen.

TABLE VI WEIGHTS IN LINGUISTIC TERMS ASSIGNED TO GOALS/CONSTRAINTS IN RESPECT OF FUNCTIONALITY

\begin{tabular}{|c|c|c|c|}
\hline Stakeholder & $\begin{array}{c}\text { goals and } \\
\text { constraints }\end{array}$ & $\begin{array}{c}\text { Range } \\
\text { Weights assigned } \\
\text { in fuzzy terms } \\
\text { representin } \\
\text { g the } \\
\text { weights }\end{array}$ \\
\hline \multirow{2}{*}{$\mathbf{S}_{\mathbf{1}}$} & $\begin{array}{c}\text { Complete reflection } \\
\text { of cutomers' } \\
\text { requirements }\end{array}$ & $\begin{array}{c}\text { Among "VLI", } \\
\text { "LI" and "I" }\end{array}$ & $(2,3,4)$ \\
\cline { 2 - 4 } & Profit & $\begin{array}{c}\text { Between "I" and } \\
\text { "HI" }\end{array}$ & $(6,7,8)$ \\
\hline
\end{tabular}


Hence final weight/priority of schedule $=5.5$

Crisp weights $\mathrm{v}_{3}$ and $\mathrm{w}_{3}$ w.r.t. goal/constraint of functionality against fuzzy weights in TABLE VI, obtained are:

For crisp value of $\mathrm{v}_{3}=(2,3,4)=(0.5) *(3.5)+(1-0.5) * 2.5=3$

Crisp value of $\mathrm{w}_{3}=(6,7,8)=(0.5) *(7.5)+(1-0.5) *(6.5)=7$

Converting these weights in $[0,1]$ :

Value of $\mathrm{v}_{3}$ in $[0,1]=\mathrm{v}_{1} /\left(\mathrm{w}_{1}+\mathrm{v}_{1}\right)=(3 /(3+7))=0.3$

Value of $\mathrm{w}_{3}$ in $[0,1]=\mathrm{w}_{1} /\left(\mathrm{w}_{1}+\mathrm{v}_{1}\right)=(7 /(7+3))=0.7$

Utilizing the membership function (6) for goal (complete reflection of customers' requirements) and (7) for constraint (profit), final weight/priority obtained for functionality $=4$ Crisp weights $\mathrm{v}_{4}$ and $\mathrm{w}_{4}$ w.r.t. goal/constraint of performance against fuzzy weights in TABLE VII can be obtained as:

$\mathrm{v}_{4}=(1,2,3)=[(2-1) *(0.5)+1,-(2-3)(0.5)+3]=[1.5,3.5]=(0.5) *(3$ $.5)+(1-0.5) * 1.5=2.5$

$\mathrm{w}_{4}=(6,7,8)=7$

Value of $\mathrm{v}_{4}$ in $[0,1]=\mathrm{v}_{4} /\left(\mathrm{w}_{4}+\mathrm{v}_{4}\right)=2.5 /(2.5+7)=0.263$

Value of $\mathrm{w}_{4}$ in $[0,1]=\mathrm{w}_{4} /\left(\mathrm{w}_{4}+\mathrm{v}_{4}\right)=(7 /(2.5+7))=0.737$

TABLE VII WEIGHTS IN LINGUISTIC TERMS ASSIGNED TO GOALS/CONSTRAINTS IN RESPECT OF PERFORMANCE

\begin{tabular}{|c|c|c|c|}
\hline Stakeholder & $\begin{array}{c}\text { goals and } \\
\text { constraints }\end{array}$ & $\begin{array}{c}\text { Weights assigned } \\
\text { in fuzzy terms }\end{array}$ & $\begin{array}{c}\text { Range } \\
\text { representing the } \\
\text { weights }\end{array}$ \\
\hline \multirow{2}{*}{$\mathbf{S}_{\mathbf{1}}$} & $\begin{array}{c}\text { Customers' } \\
\text { satisfaction }\end{array}$ & $\begin{array}{c}\text { Between "VLI" } \\
\text { and "LI" }\end{array}$ & $(1,2,3)$ \\
\cline { 2 - 4 } & Profit & $\begin{array}{c}\text { Between "I" and } \\
\text { "HI" }\end{array}$ & $(6,7,8)$ \\
\hline
\end{tabular}

For getting more accuracy, continuous interval values should be used instead of discrete such as $1,1.1 .2,2.1 \ldots 3,3.1 \ldots \ldots$ The weight/priority against performance w.r.t. $\mathrm{v}_{4}$ using $\mathrm{w}_{4}$ can be obtained on $\mathrm{x}$-axis as 3.8 .

TABLE VIII WEIGHTS IN LINGUISTIC TERMS ASSIGNED TO GOALS/CONSTRAINTS IN RESPECT OF RISK MANAGEMENT

\begin{tabular}{|c|c|c|c|}
\hline Stakeholder & $\begin{array}{c}\text { goals and } \\
\text { constraints }\end{array}$ & $\begin{array}{c}\text { Weights } \\
\text { assigned in } \\
\text { fuzzy terms }\end{array}$ & $\begin{array}{c}\text { Range } \\
\text { representing } \\
\text { the weights }\end{array}$ \\
\hline \multirow{3}{*}{$\mathbf{S}_{\mathbf{1}}$} & $\begin{array}{c}\text { Dealing with } \\
\text { failures of project }\end{array}$ & $\begin{array}{c}\text { Between } \\
\text { "VLI" }\end{array}$ & $(0,1,2)$ \\
\cline { 2 - 4 } & Cost incurred & $\begin{array}{c}\text { Between "I" } \\
\text { and "HI" }\end{array}$ & $(6,7,8)$ \\
\hline
\end{tabular}

Crisp weights $\mathrm{v}_{5}$ and $\mathrm{w}_{5}$ w.r.t. goal/constraint of risk against fuzzy weights in TABLE VIII can be obtained as:

$\mathrm{v}_{5}=(0,1,2)=[(1-0) *(0.5)+0,-(2-1)(0.5)+2]=[0.5,2.5]=(0.5) *(2$ $.5)+(1-0.5) *(0.5)=1.5$

$\mathrm{w}_{5}=(6,7,8)=7$

Value of $\mathrm{v}_{4}$ in $[0,1]=\mathrm{v}_{4} /\left(\mathrm{w}_{4}+\mathrm{v}_{4}\right)=1.5 /(1.5+7)=0.1765$

Value of $\mathrm{w}_{4}$ in $[0,1]=\mathrm{w}_{4} /\left(\mathrm{w}_{4}+\mathrm{v}_{4}\right)=(7 /(1.5+7))=0.8235$

Similarly weight/priority against risk w.r.t. $\mathrm{v}_{5}$ using $\mathrm{w}_{5}$ obtained on $\mathrm{x}$-axis is 3.6 .

Scaling the values of weights/priorities in [0,1],weights given by stakeholder $S_{1}$ w.r.t. conflicting requirements can be obtained as:

$\mathrm{S}_{1}: \mathrm{SH}=5.5 /(5.5+5+4+3.8+3.6)=0.251$

$\mathrm{S}_{1}: \mathrm{C}=5 /(5.5+5+4+3.8+3.6)=0.228$

$\mathrm{S}_{1}: \mathrm{F}=0.183$
$\mathrm{S}_{1}: \mathrm{P}=0.174$

$\mathrm{S}_{1}: \mathrm{R}=0.164$

TABLE IX WEIGHTS/PRIORITIES OF CONFLICTING REQUIREMENTS DECIDED BY STAKEHOLDER S

\begin{tabular}{|c|c|}
\hline $\begin{array}{c}\text { Conflicting Requirements } \\
\text { (in descending order of their priorities) }\end{array}$ & $\begin{array}{c}\text { Weights } \\
\text { calculated }\end{array}$ \\
\hline SH & 0.251 \\
\hline C & 0.228 \\
\hline F & 0.183 \\
\hline P & 0.174 \\
\hline R & 0.164 \\
\hline
\end{tabular}

Hence arranging all conflicting requirements in the decreasing order of values of their weights/priorities, stakeholder $S_{1}$ reaches to the preference ordering of conflicting requirements as: $\mathrm{P}_{1}=\langle\mathrm{SH}, \mathrm{C}, \mathrm{F}, \mathrm{P}, \mathrm{R}\rangle$ as shown in TABLE IX.

Similarly rest of other six stakeholders obtained their precedence ordering $P_{i}, i=1,2 \ldots n$ of conflicting requirements with their respective weights as shown below:

\section{Preference orderings Weights}

$\mathrm{P}_{1}=\langle\mathrm{SH}, \mathrm{C}, \mathrm{F}, \mathrm{P}, \mathrm{R}\rangle \quad:(0.251,0.228,0.183,0.174,0.164)$

$\left.\mathrm{P}_{3}=<\mathrm{SH}, \mathrm{R}, \mathrm{P}, \mathrm{F}, \mathrm{C}\right\rangle \quad:(0.4,0.3,0.15,0.1,0.05)$

$\mathrm{P}_{2}=\mathrm{P}_{5}=\langle\mathrm{P}, \mathrm{R}, \mathrm{C}, \mathrm{SH}, \mathrm{F}\rangle:(0.251,0.228,0.183,0.174,0.164)$

$\mathrm{P}_{4}=\mathrm{P}_{7}=\langle\mathrm{C}, \mathrm{P}, \mathrm{SH}, \mathrm{F}, \mathrm{R}\rangle:(0.356,0.301,0.229,0.089,0.025)$

$\mathrm{P}_{6}=\langle\mathrm{C}, \mathrm{SH}, \mathrm{F}, \mathrm{P}, \mathrm{R}\rangle \quad:(0.4,0.3,0.15,0.1,0.05)$

It can be seen that stakeholders $\mathrm{P}_{4}, \mathrm{P}_{6}$ and $\mathrm{P}_{7}$ preferred cost over the other estimates, while $\mathrm{P}_{3}, \mathrm{P}_{1}$ opted for schedule.

\section{Dealing with consolidated concerns of all stakeholders}

In this paper, objective is to find the desired precedence ordering which depicts the consolidated concerns of all stakeholders on which all stakeholders agree.

Using membership function in equation (8) the fuzzy social preference relation $(\mathrm{S})$ was obtained as:

$$
\mathrm{S}=\left[\begin{array}{cccccc} 
& \mathrm{C} & \mathrm{SH} & \mathrm{F} & \mathrm{P} & \mathbb{R} \\
\mathrm{C} & 0 & 0.7 & 0.86 & 0.57 & 0.57 \\
\mathrm{SH} & 0.286 & 0 & 0.86 & 0.286 & 0.57 \\
\mathrm{~F} & 0.14 & 0.14 & 0 & 0.429 & 0.7 \\
\mathrm{P} & 0.429 & 0.7 & 0.57 & 0 & 0.86 \\
\mathrm{R} & 0.429 & 0.429 & 0.286 & 0.14 & 0
\end{array}\right]
$$

E.g for pair of conflicting requirements (C, $\mathrm{SH}), 5$ stakeholders $\left(\mathrm{P}_{2}, \mathrm{P}_{4}, \mathrm{P}_{5}, \mathrm{P}_{6}, \mathrm{P}_{7}\right)$ preferred $\mathrm{C}$ over $\mathrm{SH}$. For this pair, value of membership function using (8) was computed as $5 \div 7=0.7$.

In a similar manner, other values of $\mathrm{S}$ were computed. All values of relation $S$ worked as various values of $\alpha$. Starting from $\alpha=1, \alpha$-cuts were constructed. And the process continued with decreasing value of $\alpha$ till total ordering was achieved. The $\alpha$-cuts denoted by ${ }^{\alpha} \mathrm{S}$ for various values of $\alpha$ as $1,0.86,0.7,0.57,0.429,0.286,0.14$ were obtained and are listed below:

${ }^{1} \mathrm{~S}=\emptyset$

${ }^{0.86} \mathrm{~S}=\{\langle\mathrm{C}, \mathrm{F}\rangle,\langle\mathrm{SH}, \mathrm{F}\rangle,\langle\mathrm{P}, \mathrm{R}\rangle\}$

${ }^{0.7} \mathrm{~S}=\{\langle\mathrm{C}, \mathrm{SH}\rangle,\langle\mathrm{F}, \mathrm{R}\rangle,\langle\mathrm{P}, \mathrm{SH}\rangle,\langle\mathrm{C}, \mathrm{F}\rangle,\langle\mathrm{SH}, \mathrm{F}\rangle,\langle\mathrm{P}, \mathrm{R}\rangle\}$

E.g. $\alpha-$ cut ${ }^{0.7} \mathrm{~S}$ contains all the pairs of conflicting 
requirements for which $\alpha \geq=0.7$ i.e. it consists of all pairs in $\alpha$ - cut ${ }^{0.86} \mathrm{~S}$ as well as w.r.t. the value of $\alpha=0.7$

Similarly pairs falling in next $\alpha$ - cut are shown below:

${ }^{0.57} \mathrm{~S}=\{\langle\mathrm{C}, \mathrm{P}\rangle,\langle\mathrm{C}, \mathrm{R}\rangle,\langle\mathrm{SH}, \mathrm{R}\rangle,\langle\mathrm{P}, \mathrm{F}\rangle,\langle\mathrm{C}, \mathrm{SH}\rangle,\langle\mathrm{F}, \mathrm{R}\rangle,\langle\mathrm{P}, \mathrm{SH}\rangle$ $,\langle\mathrm{C}, \mathrm{F}\rangle,\langle\mathrm{SH}, \mathrm{F}\rangle,\langle\mathrm{P}, \mathrm{R}\rangle\}$

It is seen that in $4^{\text {th }}$ iteration, total ordering was achieved at $\alpha=0.57$, therefore no more $\alpha$-cuts were required. Finally at $\alpha=0.57$ the optimum level of ordering (C, P, SH, F, R) resolving the conflicting preferences among various stakeholders was achieved.

As final obtained preference ordering $\mathrm{P}_{4}=\mathrm{P}_{7}=(\mathrm{C}, \mathrm{P}, \mathrm{SH}, \mathrm{F}$, R) belongs to stakeholder $S_{4}$ and $S_{7}$, therefore either the weights assigned by stakeholders $\mathrm{S}_{4}$ or $\mathrm{S}_{7}$ of these conflicting requirements can be opted as it is or can be mutually refined by the domain experts by calculating the variance of these weights with respect to the average values of weights of stakeholders so that refined values of weights thus obtained may be more closer to the expectations of all stakeholders. Therefore the objective is to reduce the variation or gap in between the weights of optimal ordering and the average of all weights given by other stakeholders. The variance and refined weights thus obtained can be shown in TABLE X. If value of weight of a conflicting requirement of optimum ordering is greater than the average value then it can be brought to the average value by subtracting variance from it and in case its value is lesser than the average value then gap can be reduced by adding variance in its value. If more accuracy is required then the same process can be repeated up to the satisfaction of stakeholders till variance between refined weights and average weights becomes negligible.

TABLE X REFINEMENT OF WEIGHTS REFLECTING ALL STAKEHOLDERS' EXPECTATIONS

\begin{tabular}{|c|c|c|c|c|c|}
\hline \multirow{2}{*}{$\begin{array}{c}\text { Preference } \\
\text { orderings }\end{array}$} & \multicolumn{5}{|c|}{$\begin{array}{c}\text { Conflicting } \\
\text { requirements }\end{array}$} \\
\cline { 2 - 6 } & $\mathbf{C}$ & $\mathbf{S H}$ & $\mathbf{F}$ & $\mathbf{P}$ & $\mathbf{R}$ \\
\hline $\mathbf{P}_{\mathbf{1}}$ & 0.228 & 0.251 & 0.183 & 0.174 & 0.164 \\
\hline $\mathbf{P}_{\mathbf{2}}$ & 0.183 & 0.174 & 0.164 & 0.251 & 0.228 \\
\hline $\mathbf{P}_{\mathbf{3}}$ & 0.05 & 0.4 & 0.1 & 0.15 & 0.3 \\
\hline $\mathbf{P}_{\mathbf{4}}$ & $\mathbf{0 . 3 5 6}$ & $\mathbf{0 . 2 2 9}$ & $\mathbf{0 . 0 8 9}$ & $\mathbf{0 . 3 0 1}$ & $\mathbf{0 . 0 2 5}$ \\
\hline $\mathbf{P}_{\mathbf{5}}$ & 0.183 & 0.174 & 0.164 & 0.251 & 0.228 \\
\hline $\mathbf{P}_{\mathbf{6}}$ & 0.4 & 0.3 & 0.15 & 0.1 & 0.05 \\
\hline $\mathbf{P}_{\mathbf{7}}$ & $\mathbf{0 . 3 5 6}$ & $\mathbf{0 . 2 2 9}$ & $\mathbf{0 . 0 8 9}$ & $\mathbf{0 . 3 0 1}$ & $\mathbf{0 . 0 2 5}$ \\
\hline Average & $\mathbf{0 . 2 5 0 8 5}$ & $\mathbf{0 . 2 5 1}$ & $\mathbf{0 . 1 3 4}$ & $\mathbf{0 . 2 1 8 2 8}$ & $\mathbf{0 . 1 4 5 7 1}$ \\
\hline $\begin{array}{c}\text { Variance } \\
\text { of } \mathbf{P}_{7} / \mathbf{P}_{\mathbf{4}} \\
\text { from } \\
\text { average }\end{array}$ & $\mathbf{0 . 0 0 5 5 3}$ & $\mathbf{0 . 0 0 0 2 4}$ & $\mathbf{0 . 0 0 1}$ & $\mathbf{0 . 0 0 3 4 2}$ & $\mathbf{0 . 0 0 7 3}$ \\
\hline $\begin{array}{c}\text { Refined } \\
\text { value }\end{array}$ & $\mathbf{0 . 3 5 0 4 7}$ & $\mathbf{0 . 2 2 9 2 4}$ & $\mathbf{0 . 0 9 0}$ & $\mathbf{0 . 2 9 7 5 8}$ & $\mathbf{0 . 0 3 2 3}$ \\
\hline
\end{tabular}

Hence from TABLE $X$, after rounded off the refined weights w.r.t. conflicting requirements are obtained as:

$\mathrm{C}: \mathrm{X}_{1}=0.35, \mathrm{SH}: \mathrm{X}_{2}=0.23, \mathrm{~F}: \mathrm{X}_{3}=0.09, \mathrm{P}: \mathrm{X}_{4}=0.30, \mathrm{~F}: \mathrm{X}_{5}=0.03$

Estimates of these conflicting requirements pertaining to various goals are ascertained by developers in TABLE XI. These estimates are used for computation of agent_points for $\mathrm{AC}_{1}$. Same process is extended for other ACs also.

As observed from TABLE XI:

Minimum value of cost for a goal $=200 \$$

And value of cost for goal $\mathrm{G}_{11}=300 \$$

TABLE XI ESTIMATES OF C, SH, F, P, R FOR VARIOUS GOALS W.R.T. $\mathrm{AC}_{1}$

\begin{tabular}{|c|c|c|c|c|c|}
\hline Goals & C ( \$) & SH (days) & $\begin{array}{c}\text { F(function } \\
\text { points) }\end{array}$ & P(secs) & R \\
\hline $\mathrm{G}_{11}$ & 300 & 6 & 8 & 0.07 & 1 \\
\hline $\mathrm{G}_{12}$ & 400 & 7 & 9 & 0.05 & 2 \\
\hline $\mathrm{G}_{13}$ & 200 & 4 & 5 & 0.3 & 2 \\
\hline $\mathrm{G}_{14}$ & 500 & 9 & 11 & 0.04 & 2 \\
\hline $\mathrm{G}_{15}$ & 800 & 16 & 14 & 0.02 & 2 \\
\hline
\end{tabular}

TABLE XII GOAL_POINTS $\left(\mathrm{GP}_{\mathrm{ij}}\right)$ FOR $\mathrm{G}_{\mathrm{ij}}$ W.R.T AC

\begin{tabular}{|l|l|}
\hline Goals & $\begin{array}{l}\text { Goal } \\
\text { Points }\end{array}$ \\
\hline $\mathrm{GP}_{11}$ & 0.558 \\
\hline $\mathrm{GP}_{12}$ & 0.491 \\
\hline $\mathrm{GP}_{13}$ & 0.705 \\
\hline $\mathrm{GP}_{14}$ & 0.448 \\
\hline $\mathrm{GP}_{15}$ & 0.492 \\
\hline
\end{tabular}

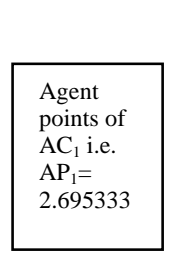

Similarly other values for $\mathrm{SH}, \mathrm{F}, \mathrm{P} \& \mathrm{R}$ for $\mathrm{G}_{11}$ were observed. These were substituted in equations (9) and (10) to compute the goal_points shown in TABLE XII and agent_points in TABLE XIII respectively.

This work presents a fuzzy decision making approach to capture individual and consolidated concerns pertaining to conflicting opinions of various stakeholders. Deciding preference ordering of imprecise and fuzzy conflicting requirements by a stakeholder is a matter of individual concerns and obtaining the preference ordering on which all stakeholders would agree, is a problem of consolidated concerns. This paper addresses the fuzziness and vagueness associated with several stakeholders' concerns using Fuzzy Decision-Making and facilitates the developers in prioritizing and deciding which agents are viable to achieve in the limited constraints. Future study would prove that the system built using the proposed methodology results in higher stakeholders' satisfaction.

\section{REFERENCES}

[1] Sabrina Ahmad, Negotiation in the Requirements Elicitation and Analysis Process, 2008, IEEE , ISBN: 978-0-7695-3100-7,pp. 683 689

[2] Hoh In, Visuallization Issues for Software Requirements Negotiation,2001,IEEE, ISBN: 0-7695-1372-7,pp. 10 - 15

[3] Sheela Ramanna, Requirements Interaction and Conflicts A Rough Set Approach,2007,IEEE

[4] Yuji Kyoya, Priority Assessment of Software Requirements from Multiple Perspective, ISBN: 0-7695-2209-2,volume:1, pp:410-415, 2004, IEEE

[5] Watson, A. ,Reflections on Requirements Engineering,2008,IEEE, ISBN: 978-0-7695-3373-5,pp. xxxiii - xxxiii

[6] John Yen and W. Amos Tiao, A Systematic Tradeoff Analysis for Conflicting Imprecise Requirements,1997,IEEE ISBN:0-8186-7740-6,pp.87, ISBN:0-8186-7740-6

[7] Dan Port Alexy Okov, Using Simulation to Investigate Requirements Prioritization Strategies, IEEE, 2008, pp: 268-277, ISBN 978-1-4244-2187-9 
[8] Andrea Herrmann, Requirements Prioritization Based on Benefit and Cost Prediction: An Agenda for Future Research, 2008, IEEE, ISBN: 978-0-7695-3309-4,pp:125-134

[9] Joachim Karlsson, Software Requirements Prioritizing, ISBN: 0-8186-7252-8, 1996, IEEE, pp:110-116

[10] Laurent, P. Towards Automated Requirements Triage, 2007, IEEE, ISBN: 978-0-7695-2935-6,pp.131-140 13

[11] Eric Yu, Requirements Engineering for Large Scale Multi-Agent Systems, Vol. 2603, 2003, PP.77-148

[12] George J. Klir, Fuzzy Sets and Fuzzy Logic, PHI publications, 1995, ISBN:81-203-1136-1

[13] Yajun Yang, Evaluation of English Textbook Using Fuzzy Analytic Hier archy Process, IEEE, 2008

[14] Y.H. Lin, Prioritization of Competitive Priority in Cleaner Production Implementation, IEEE, 2007, pp: 104-108, ISBN: 978-1-4244-1529-8

[15] John Yen, Fuzzy Logic Intelligence, Control and Information, Pearson publications, 2006, ISBN:978-81-317-0534-6

[16] Kwang H. Lee, First Course On Fuzzy Theory And Applications

[17] Zhigang Lian, A Novel Method of Ranking Fuzzy Numbers for Decision-making Problems, IEEE,2006, Volume: 1, pp: 354-360, ISBN: 0-7695-2528-8

[18] Janusz Kacprzyk, Fuzzy Preferences as a Convenient Tool in Group Decision Making and a Remedy for Voting Paradoxes, 2009, springer,ISSN: 1860-0808, pp. 345-360

[19] Faiyaz Doctor, A Fuzzy Based Agent for Group Decision Support of Applicants Ranking within Recruitment Systems, 2009, IEEE, pp.8-15

[20] Ching-Hsue Cheng, A Simple Group Decision Making Method, 1999 IEEE, volume 2, pp.910-915

[21] Da Ruan,Fuzzy group decision-making for facility location selection,2003,Portal, ISSN:0020-0255, pp.135-153

[22] Zbigniew Pasek, Modeling of Individual Decision Making In Mass Customization Markets,2006,IEEE, ISBN:1-4244-0501-7,pp. 2288 2288

[23] Amir Sayed Danesh, Study of Prioritization Techniques using Students as Subjects, 2009, IEEE, ISBN: 978-0-7695-3595-1

[24] Vibha Gaur, Anuja Soni, Punam Bedi, An Agent Oriented Approach to Requirements Engineering, 2010 IEEE 2nd International Advance Computing Conference, pp.449-454

[25] Hans.I. Zimmerman, Fuzzy Sets, Decision Making and Expert Systems, International series in Management Science/Operations, Kluwer Academic Publishers

[26] U. Kaymak, A Parametric Generalized goal function for Fuzzy Decision Making with unequally weighted objectives,1993,IEEE, ISBN: 0-7803-0614-7,pp. 1156 - 1160 vol.2

[27] Md. Rizwan Beg, An Approach for Requirement Priortization using B-Tree, 2008, IEEE, ISBN:978-0-7695-3267-7

[28] Vibha Gaur, Anuja Soni, Punam Bedi, An Application of Multi-Person Decision-Making Model for Negotiating and Prioritizing Requirements in Agent-Oriented Paradigm, 2010 International Conference on Data Storage and Data Engineering, IEEE,pp. 164-168

[29] U. Kaymak, Weighted Constraint Aggregation in Fuzzy Optimization,2003, Springer, pp. 61-78(18)

[30] Hepu Deng, MultiCriteria Analysis with Fuzzy Pairwise Comparison, IEEE,1999, Volume: 2, pp: 726-731, ISBN: 0-7803-5406-0

[31] U. Kaymak, A Sensitivity-Based Analysis of Weighted Fuzzy Aggregation, 1998, IEEE, ISBN: 0-7803-4863-X , pp:755 - 760 vol.1 